\title{
Another Look at Portfolio Turnover and Mutual Fund Performance
}

\author{
Confidence W. Amadi ${ }^{1} \&$ Felicia Y. Amadi ${ }^{1}$ \\ ${ }^{1}$ Elizabeth City State University, Weeksville Road, Elizabeth City, USA \\ Correspondence: Felicia Y. Amadi, Elizabeth City State University, 1704 Weeksville Road, Elizabeth City, NC \\ 27909, USA. Tel: 1-252-335-3497. E-mail: fyamadi@ecsu.edu
}

Received: August 5, 2017

Accepted: August 20, 2017

Online Published: September 5, 2017

doi:10.5539/ijef.v9n10p95

URL: https://doi.org/10.5539/ijef.v9n10p95

\begin{abstract}
The objective of this study was to investigate the factors that correlated with mutual fund portfolio turnover using the variables that are associated with studies on portfolio turnover. Most studies on portfolio turnover considered it as an independent variable in explaining the performance of mutual funds. We take a different approach and treat turnover as the dependent variable. Our regression analysis show that the portfolio manager's tenure explains the variability in portfolio turnover. We also find that the one-year portfolio returns and assets under management strongly correlates with portfolio turnover.
\end{abstract}

Keywords: portfolio turnover, mutual fund performance, mutual fund size, market capitalization, mutual fund style objective, mutual fund manager tenure, Sharpe ratio, Beta, standard deviation, expense ratio

\section{Introduction}

The objective of this paper is to investigate the relationship between fund performance/return and portfolio turnover after controlling for risk and expense. Efficient market theories assert that one cannot consistently profit from publicly available information. However, it is possible to consistently earn profit by trading on non-public information. Thus, portfolio turnover is an indication of portfolio manager's intent to profit from their ability to uncover nonpublic information and hence trade securities that are mispriced in the market.

As reported by Bauman et al (2005), the literature has identified six plausible reasons for high portfolio turnover as:

- Investors preference for short-term performance which affects the flow of investment funds.

- Portfolio managers engaging in momentum strategy wherein they buy stocks with rising prices and sell those with falling prices

- Because some investors rank portfolio managers, portfolio managers get swept into crowd psychology and seek safety in numbers.

- Overconfidence on the part of some portfolio manager's ability to distinguish between attractive and unattractive stocks and hence seek to earn abnormal returns.

- Other reasons for high portfolio turnover is centered around liquidity needs, tax considerations, and portfolio risk rebalancing.

- Lastly, there is the issue of high management fees charged by some portfolio managers and thus trading is used as a justification for the fees.

Whatever the reason for the high turnover, the question is does high portfolio turnover enhance the value of the fund? Several studies have attempted to answer this question using various techniques and methodology. Using data from 1994 through 2006 on the real estate mutual funds, Chou and Hardin III (2014) examined the relationship between fund performance and fund flows and between fund size and fund performance. In addition, they also investigated whether fund managers with selection ability can outperform the market. They find that fund flows and increased fund size have a negative impact on fund performance and that skilled managers cannot generally outperform the market on an after expense basis. However, they also find that real estate mutual fund managers have the ability to select firms and form portfolios that outperform relevant benchmarks before expenses. In addition, their study shows that turnover ratios are positively related to fund performance for small size fund groups, but for the pooled study sample, turnover ratio has little or no effect on future fund 
performance.

Fan and Addams (2012) examined the market behavior of U.S.-based international funds that invests solely in the international equity markets from 2005 to 2009. Using three-year annualized return, five-year annualized return, sharp ratio, alpha, and Morningstar rating as measures of performance, they find that turnover ratio is significantly negatively related to all performance measures. They show that although turnover ratios do not enhance fund expense ratios, they however, lead to worse fund performance. Chang et al. (2012) compared the performance of green and traditional mutual funds in the U.S.A. They find that green mutual funds have higher expense ratios and lower turnover rates than traditional mutual funds. Contrastingly, they also have lower annualized returns than their traditional counterpart. This finding goes against the argument that high turnover rates lead to high expense rations and lower returns.

Bello and DeRidder (2011) in their study of domestic equity mutual funds from 1990 to 2010, document that an average portfolio turnover of $96 \%$ in a sample of 2,900 actively managed domestic equity mutual funds listed in Morningstar Principia database. With an average securities holding of 139, this suggests that the average portfolio manager bought and replaced their entire holdings approximately every 12.5 months. This level of activity suggests that there must be some economic value associated with active portfolio management. Low (2008) in a cross-sectional analysis of Malaysian unit trust fund expense ratios, after controlling for size, fund family, risk and fund objective, find that high portfolio turnover leads to high expense ratios.

Evans (2008) examined the relationship between a fund manager's personal fund investment and the mutual fund performance. After controlling for such factors as fund style, low or negative net flows, unrealized capital gains, age of funds and tenure of fund manager, Evans show that annual fund returns in excess of fund-style means are statistically lower, at the $1 \%$ level, for funds where the fund manager has a low level of personal investment (under $\$ 100,000$ ). In addition, they find that the mean-adjusted turnover levels are inversely related to fund ownership. The study concludes that fund manager's personal investment findings are consistent aligning decision maker and shareholder interests.

In a cross-sectional analysis of the performance of mutual funds that hold a small (10-30) stocks in their portfolio, Kaushik and Barnhart (2008) find that the effect of portfolio turnover depends on whether the portfolio is a winner or loser. Winners and Losers were "defined as those funds in the top and bottom quartiles based on excess return (monthly fund return minus corresponding month T-bill return)". For the Winner portfolio, there exists a positive relationship between the abnormal performance and portfolio turnover with a coefficient of $0.021(t=3.94)$ that is significant at the 1 percent level. For the Loser portfolio the coefficient is negative $(-0.034$, $\mathrm{t}=-6.24)$ and significant also at the 1 percent level. Thus, turnover has in absolute terms a higher effect on abnormal performance for Loser portfolio than for Winner portfolio.

Tower and Zheng (2008) evaluated the performance of 51 mutual fund families from 1994 through 2005. They find that fund families with loads and high expenses and high turnover underperformed their corresponding indexes. On the contrary, no load and low expense fund families with low portfolio turnover beat their corresponding indexes. Bliss et al (2008) investigated the difference in the performance characteristics of individually-managed versus team-managed mutual funds. They find no significant difference in the overall turnover between team-managed and individually managed funds. However, they find that regardless of the turnover or trading volume, the level of fees and loads were significantly higher for individually managed funds. They also find that team managed funds were much more likely to perform at their category averages. In addition, their study shows that team-managed funds exhibit significantly lower risk than the individually-managed funds.

Snow (2008) examined the factors that determined the fund expense ratio for Malaysian unit trust funds. The study shows that fund size, fund family, portfolio turnover and risk as measured by beta are the primary determinants of expense ratio. The study indicates that there is a highly significant negative relationship between fund turnover and managerial expense ratio. However, the study does not address the reason behind the turnover whether it is harmful or beneficial to the fund. This is the primary objective of this paper. Cakici et al. (2002) examined the impact of portfolio turnover on the performance of closed -end mutual funds under different trading cost environment. They find that at low levels of trading costs, closed-end mutual funds outperformed their benchmarks. However, at moderate to high trading cost, portfolios with "less-frequent rebalancing and tight turnover constraints" outperformed their benchmarks and other portfolios. They conclude that the ability to earn excess returns depended on trading cost environment.

Bauman et al. (2005) compared the returns on stocks bought with the return on stocks sold by investment advisers to see if the turnover of stocks in actively managed portfolios enhances portfolio performance. They 
find that many investment advisers have the skill set to identify stocks to buy that earns a higher risk-adjusted return than the market as well as a higher return per unit of risk than the stocks they sell. This suggest that portfolio turnover adds value to the portfolio for many of the advisers. Redman and Gullett (2007) examined the factors that determine the risk-adjusted returns for bond funds. They find that the factors depend on the tad treatment of the bond fund. For taxable bond funds, taxes, fund age, and operating expenses are the key determinants of risk-adjusted return. For municipal bonds, fund expenses and average duration of the bonds are the key determinants of return. In neither class of bonds was turnover found to be a factor. However, the high negative significance of expenses might be partially attributable to trading expenses and hence portfolio turnover.

Haslem et al. (2008) studied the performance and characteristics of actively managed retail mutual funds. Using the Sharpe ratio and Jensen's alpha and Russell-index-adjusted returns as performance measures, they find that the turnover ratio is negative and highly significant for one-, five-, ten-, and fifteen-year annualized Russell index-adjusted returns. They show that turnover activity trends upwards when moving from lower to higher expense ratio classes. Taylor and Yoder (1994) investigated the relationship between mutual fund trading activity and investor utility using stochastic dominance tests to determine whether investors prefer the returns associated with high-turnover funds or low-turnover funds. Their sample consists of maximum capital gain funds because of their high turnovers. They ranked the sample of 727 observations from lowest to highest turnover and grouped them into quintiles. Based on second order stochastic dominance tests, which assumes that investors are risk averse, only the highest turnover quintile was in the efficient set. They show that a risk averse investor would prefer the highest turnover group over any of the other four groups. Thus, they conclude that the trading activities of mutual fund managers can alter return distributions in such a way as to enhance investor utility.

Ippolito and Turner (1987) examined the relationship between turnover, fees and pension plan performance. They argued that in an efficient market, "turnover policies are unrelated to returns, net of turnover expenses." Their results show no evidence that plans with high turnover performed worse, net of expenses, than those with lower turnover.

Peterson and Riepe (2010) argue that the relationship between turnover and portfolio performance is more nuanced than conventional wisdom would suggest. Based on five factor approach i.e.
i. Use of future relative fund performance
ii. Control for more variables
iii. Nonlinearity
iv. Category dependent
v. Skill dependent

They conclude that portfolio turnover is rarely a significant variable except in the case of funds with "extremely high levels of turnover in the domestic small value and international small cap categories." Their results indicate that in a category by category regression analysis, turnover is more costly for categories that trade in securities with higher transactions costs.

Several if not most of the studies on portfolio turnover have relied on a regression analysis that considers turnover as an explanatory variable with the portfolio performance serving as the dependent variable. This study follows a different approach. The dependent variable is the portfolio turnover. Since most of the studies contend that portfolio turnover on average do not earn back the increase in trading and other operating expense, this present study seeks to identify the determinants of a mutual fund portfolio turnover. The rest of the paper is organized as follows: section II addresses the data and methodology, section III presents the results. And section IV concluding remarks.

\section{Data and Methodology}

The data for this study was obtained from Fidelity.com website on mutual funds on June 11, 2017 covering US equity funds covering all nine investment objective groups ranging from large cap value to small cap growth. Each dataset lists fund information including current manager's tenure, 1-, 3-, 5- and 10-year annualized returns, expense ratio, Sharpe ratio, turnover and beta.

Consistent with the objective of this study, a regression analysis will be performed to determine the relationship, if any, between the variables that explain mutual fund performance and the fund's portfolio turnover. The following model will be estimated:

$$
\text { Turnover }=f\{\text { style, tenure, return, expense, standard deviation, beta, Sharpe ratio, assets }\}
$$


The style represents the investment objective group. For this study, style will be broken down into three groups representing large medium and small capitalization. Another grouping will be based on income, blend and growth objectives. Tenure represents the length of time the manager has been at the job with the fund. This variable will have three categories as follows: up to 5

Equation 1 will be estimated for each of the four-holding period returns to investigate which period has the most impact, if any, on portfolio turnover. The expense ratio is the gross expense ratio, and is calculated as of 5/31/2017 as well as the standard deviation, beta and Sharpe ratio. Because of the large variance in the total assets under management, the natural log of the size of the assets will be used in the estimation. Specifically, the OLS regression model will be as follows:

$$
Y=\alpha_{i}+\beta_{1 i} X_{1 i}+\beta_{2} X_{2}+\beta_{3} X_{3}+\beta_{4} X_{4}+\beta_{5} X_{5}+\beta_{6} X_{6}+\beta_{7} X_{7}+\beta_{8} X_{8}+\beta_{9} X_{9}+\beta_{10} X_{10}+\beta_{11} X_{11}+\varepsilon_{i}
$$

Where:

$X_{1 i}=$ YTD, 1-, 3-, 5- and 10-year portfolio return;

$X_{2}=$ Portfolio standard deviation;

$X_{3} \& X_{4}=$ dummy variables for portfolio style objective Based on either capitalization or objective;

$X_{5}$ through $X_{7}=$ dummy variable for manager tenure grouped as less than or equal to 5 years, greater than 5 years but less than or equal to 10 years, greater than 10 years but less than or equal to 15 years, and greater than 15 years;

$X_{8}=$ Beta of the portfolio;

$X_{9}=$ Sharpe Ratio;

$X_{10}=$ Expense ratio (either gross or net);

$X_{I I}=$ natural $\log$ of the assets under management.

\section{Results}

In order to investigate the factors that affect the turnover of a mutual fund portfolio, two sets of regressions were run based on market capitalization and style dimensions. A total of twelve regression models was investigated. In the first two regressions, all of the five return measures along with the control variables were used as explanatory variables. In regression 1, the explanatory variables were statistically significant in explaining the variation in portfolio turnover. The results of the regression are presented in Table 1.

Table 1. Capitalization regression results

\begin{tabular}{|c|c|c|c|c|c|}
\hline \multicolumn{6}{|c|}{ Model Summary } \\
\hline Model & $\mathrm{R}$ & R Square & Adjusted R Square & \multicolumn{2}{|c|}{ Std. Error of the Estimate } \\
\hline 1 & $.659^{\mathrm{a}}$ & .434 & .274 & \multicolumn{2}{|c|}{.356110537000000} \\
\hline \multicolumn{6}{|c|}{$\begin{array}{l}\text { a. Predictors: (Constant), Beta, LnAssets, Medium, TG5LE10, \%R3 Yr, \%R5Yr, GT10LE15, Std Dev, \%YTD, GrossExp, } \\
\text { T5orLess, \%R10Yr, \%R1 Yr, Sharpe R, Large }\end{array}$} \\
\hline \multicolumn{6}{|c|}{ ANOVA $^{\mathrm{a}}$} \\
\hline Model & & Sum of Squares & Mean Square & $\mathrm{F}$ & Sig. \\
\hline \multirow[t]{3}{*}{1} & Regression & 5.158 & .344 & 2.712 & $.004^{b}$ \\
\hline & Residual & 6.721 & .127 & & \\
\hline & Total & 11.879 & 68 & & \\
\hline
\end{tabular}

a. Dependent Variable: Turnover

b. Predictors: (Constant), Beta, LnAssets, Medium, TG5LE10, \%R3 Yr, \%R5Yr, GT10LE15, Std Dev, \%YTD, GrossExp, T5orLess, \%R10Yr, \%R1 Yr, Sharpe R, Large

\begin{tabular}{|c|c|c|c|c|c|c|}
\hline \multicolumn{7}{|c|}{ Coefficients $^{\mathrm{a}}$} \\
\hline & & \multicolumn{2}{|c|}{ Unstandardized Coefficients } & \multicolumn{2}{|c|}{ Standardized Coefficients } & \multirow[b]{2}{*}{ Sig. } \\
\hline \multicolumn{2}{|c|}{ Model } & $\mathrm{B}$ & Std. Error & Beta & $\mathrm{t}$ & \\
\hline 1 & (Constant) & -.310 & .916 & & -.339 & .736 \\
\hline & Large & -.239 & .362 & -.282 & -.659 & .513 \\
\hline & Medium & -.176 & .278 & -.196 & -.636 & .528 \\
\hline & $\%$ YTD & .004 & 018 & .037 & .206 & .838 \\
\hline & $\% \mathrm{R} 1 \mathrm{Yr}$ & .034 & .020 & .350 & 1.702 & .095 \\
\hline & $\% \mathrm{R} 3 \mathrm{Yr}$ & -.040 & .039 & -.221 & -1.033 & .306 \\
\hline & $\% \mathrm{R} 5 \mathrm{Yr}$ & .027 & .017 & .222 & 1.556 & .126 \\
\hline & $\% \mathrm{R} 10 \mathrm{Yr}$ & .024 & .026 & .154 & .907 & .369 \\
\hline & GrossExp & .017 & 180 & 014 & .092 & .927 \\
\hline
\end{tabular}




\begin{tabular}{lccccc}
\hline T5orLess & .439 & .172 & .414 & 2.553 & .014 \\
TG5LE10 & .267 & .150 & .322 & 1.786 & .080 \\
GT10LE15 & .104 & .165 & .095 & .632 & .530 \\
LnAssets & -.066 & .038 & -.227 & -1.751 & .086 \\
Std Dev & .000 & .096 & .001 & .004 & .997 \\
Sharpe R & -.028 & .549 & -.013 & -.050 & .960 \\
Beta & .584 & .797 & .192 & .733 & .467 \\
\hline
\end{tabular}

a. Dependent Variable: Turnover

The model had an adjusted R-squared of $27.4 \%$ with a p-value of 0.004 . Of the return variables, only the one-year return was significant with a coefficient of 0.02 and t-statistic of 1.702 and p-value of 0.095 . Two measures of manager tenure (T5orless and TG5LE10) were significant with a t-statistic of 2.553 and 1.786 respectively. The p-values were 0.014 and 0.08 , respectively. Thus, manager's tenure equal to or less than ten years was positively related to the portfolio turnover. The last significant variable was the size (LnAssets) with a t-statistic of -1.751 and a p-value of 0.086 This indicates that the larger the portfolio, the less than turnover.

In regression 2 , the style dimension was investigated with all the explanatory variables as in regression 1 . The results, presented in Table 2, are similar to those regression 1 with manager tenure and one-year return being the only statistically significant variables. The adjusted R-squared was $27.5 \%$ with a p-value of 0.004 . The size of the portfolio was marginally significant at 0.134 and negative.

Table 2. Style objective regression results

\begin{tabular}{|c|c|c|c|c|c|c|}
\hline \multicolumn{7}{|c|}{ Model Summary } \\
\hline Model & $\mathrm{R}$ & R Square & justed R Square & \multicolumn{3}{|c|}{ Std. Error of the Estimate } \\
\hline 1 & $.659^{\mathrm{a}}$ & .435 & .275 & \multicolumn{3}{|c|}{.356000110000000} \\
\hline \multicolumn{7}{|c|}{$\begin{array}{l}\text { a. Predictors: (Constant), Blend, GT10LE15, \%R3 Yr, LnAssets, Beta, \%R5Yr, T5orLess, Std Dev, \%YTD, GrossExp, \%R10Yr, Value, } \\
\text { TG5LE10, \%R1 Yr, Sharpe R }\end{array}$} \\
\hline \multicolumn{7}{|c|}{ ANOVAa } \\
\hline Model & & Sum of Squares & df & Mean Square & F & Sig. \\
\hline \multirow[t]{3}{*}{1} & Regression & 5.162 & 15 & .344 & 2.715 & $.004^{\mathrm{b}}$ \\
\hline & Residual & 6.717 & 53 & .127 & & \\
\hline & Total & 11.879 & 68 & & & \\
\hline
\end{tabular}

a. Dependent Variable: Turnover

b. Predictors: (Constant), Blend, GT10LE15, \%R3 Yr, LnAssets, Beta, \%R5Yr, T5orLess, Std Dev, \%YTD, GrossExp, \%R10Yr, Value, TG5LE10, \%R1 Yr, Sharpe R

\begin{tabular}{|c|c|c|c|c|c|c|}
\hline \multicolumn{7}{|c|}{$\begin{array}{cc}\text { Coefficients }^{\mathrm{a}} \\
\end{array}$} \\
\hline \multirow[b]{2}{*}{ Mod } & & \multicolumn{2}{|c|}{ Unstandardized Coefficients } & \multicolumn{2}{|c|}{ Standardized Coefficients } & \multirow[b]{2}{*}{ Sig. } \\
\hline & & B & Std. Error & Beta & $\mathrm{t}$ & \\
\hline \multirow[t]{16}{*}{1} & (Constant) & -.308 & .914 & & -.337 & .737 \\
\hline & $\%$ YTD & -.003 & .022 & -.029 & -.135 & .893 \\
\hline & $\% \mathrm{R} 1 \mathrm{Yr}$ & .038 & .022 & .387 & 1.705 & .094 \\
\hline & $\% \mathrm{R} 3 \mathrm{Yr}$ & -.041 & .039 & -.229 & -1.064 & .292 \\
\hline & $\% \mathrm{R} 5 \mathrm{Yr}$ & .024 & .017 & .200 & 1.438 & .156 \\
\hline & $\% \mathrm{R} 10 \mathrm{Yr}$ & .021 & .026 & .136 & .806 & .424 \\
\hline & GrossExp & .064 & .184 & .053 & .346 & .731 \\
\hline & T5orLess & .430 & .168 & .406 & 2.556 & .014 \\
\hline & TG5LE10 & .247 & .146 & .297 & 1.686 & .098 \\
\hline & GT10LE15 & .087 & .164 & .080 & .534 & .595 \\
\hline & LnAssets & -.060 & .039 & -.204 & -1.524 & .134 \\
\hline & Std Dev & .031 & .070 & .133 & .436 & .664 \\
\hline & Sharpe R & -.151 & .555 & -.073 & -.272 & .786 \\
\hline & Beta & .159 & .440 & .052 & .362 & .719 \\
\hline & Value & -.098 & .166 & -.110 & -.587 & .560 \\
\hline & Blend & -.017 & .139 & -.020 & -.124 & .902 \\
\hline
\end{tabular}

a. Dependent Variable: Turnover

To investigate the return horizon that had the most impact on the turnover, meaning the manager's target investment horizon, the regression was run with each of the returns and the other predictor variables using only the capitalization dimension. The results are presented in tables 3 through 7. 
Table 3. \% YTD capitalization regression results

\begin{tabular}{|c|c|c|c|c|c|c|}
\hline \multicolumn{7}{|c|}{ Model Summary } \\
\hline Model & $\mathrm{R}$ & R Square & Adjusted R Square & \multicolumn{3}{|c|}{ Std. Error of the Estimate } \\
\hline 1 & $.576^{\mathrm{a}}$ & .332 & .203 & \multicolumn{3}{|c|}{.373190305000000} \\
\hline \multicolumn{7}{|c|}{ a. Predictors: (Constant), Medium, LnAssets, Beta, TG5LE10, \%YTD, GT10LE15, Std Dev, GrossExp, T5orLess, Sharpe R, Large } \\
\hline \multicolumn{7}{|c|}{ ANOVA $^{\mathrm{a}}$} \\
\hline Model & & Sum of Squares & df & Mean Square & $\mathrm{F}$ & Sig. \\
\hline \multirow[t]{3}{*}{1} & Regression & 3.941 & 11 & .358 & 2.572 & $.010^{\mathrm{b}}$ \\
\hline & Residual & 7.938 & 57 & .139 & & \\
\hline & Total & 11.879 & 68 & & & \\
\hline \multicolumn{7}{|c|}{ a. Dependent Variable: Turnover } \\
\hline \multicolumn{7}{|c|}{ b. Predictors: (Constant), Medium, LnAssets, Beta, TG5LE10, \%YTD, GT10LE15, Std Dev, GrossExp, T5orLess, Sharpe R, Large } \\
\hline \multicolumn{7}{|c|}{ Coefficients $^{\mathrm{a}}$} \\
\hline & & \multicolumn{2}{|c|}{ Unstandardized Coefficients } & \multicolumn{2}{|c|}{ Standardized Coefficients } & \multirow[b]{2}{*}{ Sig. } \\
\hline Model & & $\mathrm{B}$ & Std. Error & Beta & $\mathrm{t}$ & \\
\hline \multirow[t]{12}{*}{1} & (Constant) & -.392 & .832 & & -.471 & .639 \\
\hline & $\%$ YTD & .027 & .016 & .269 & 1.748 & .086 \\
\hline & GrossExp & .110 & .185 & .091 & .593 & .556 \\
\hline & T5orLess & .307 & .165 & .289 & 1.853 & .069 \\
\hline & TG5LE10 & .237 & .141 & .285 & 1.683 & .098 \\
\hline & GT10LE15 & .175 & .164 & .160 & 1.069 & .289 \\
\hline & LnAssets & -.047 & .039 & -.161 & -1.204 & .234 \\
\hline & Std Dev & .086 & .082 & .376 & 1.051 & .298 \\
\hline & Sharpe R & -.329 & .389 & -.160 & -.845 & .402 \\
\hline & Beta & .000 & .788 & .000 & .000 & 1.000 \\
\hline & Large & .119 & .354 & .141 & .337 & .738 \\
\hline & Medium & .044 & .277 & .048 & .157 & .875 \\
\hline
\end{tabular}

Table 4. \%R1Yr capitalization regression results

\begin{tabular}{|c|c|c|c|c|c|c|}
\hline \multicolumn{7}{|c|}{ Model Summary } \\
\hline Model & $\mathrm{R}$ & R Square & \multicolumn{2}{|c|}{ Adjusted R Square } & \multicolumn{2}{|c|}{ Std. Error of the Estimate } \\
\hline 1 & $.610^{\mathrm{a}}$ & .372 & \multicolumn{2}{|c|}{.251} & \multicolumn{2}{|c|}{.361746120000000} \\
\hline \multicolumn{7}{|c|}{ a. Predictors: (Constant), \%R1 Yr, T5orLess, Sharpe R, GT10LE15, Medium, LnAssets, Beta, GrossExp, TG5LE10, Std Dev, Lar } \\
\hline \multicolumn{7}{|c|}{ ANOVA $^{\mathrm{a}}$} \\
\hline \multirow{4}{*}{$\frac{\text { Model }}{1}$} & & Sum of Squares & df & Mean Square & $\mathrm{F}$ & Sig. \\
\hline & Regression & 4.420 & 11 & .402 & 3.071 & $.003^{\mathrm{b}}$ \\
\hline & Residual & 7.459 & 57 & .131 & & \\
\hline & Total & 11.879 & 68 & & & \\
\hline
\end{tabular}

a. Dependent Variable: Turnover

b. Predictors: (Constant), \%R1 Yr, T5orLess, Sharpe R, GT10LE15, Medium, LnAssets, Beta, GrossExp, TG5LE10, Std Dev, Large

\begin{tabular}{|c|c|c|c|c|c|c|}
\hline \multicolumn{7}{|c|}{ Coefficients $^{\mathrm{a}}$} \\
\hline & & \multicolumn{2}{|c|}{ Unstandardized Coefficients } & \multicolumn{2}{|c|}{ Standardized Coefficients } & \multirow[b]{2}{*}{ Sig. } \\
\hline \multicolumn{2}{|c|}{ Model } & $\mathrm{B}$ & Std. Error & Beta & $\mathrm{t}$ & \\
\hline \multirow[t]{12}{*}{1} & (Constant) & .090 & .838 & & .108 & .915 \\
\hline & GrossExp & .038 & .181 & .032 & .211 & .833 \\
\hline & T5orLess & .383 & .162 & .361 & 2.368 & .021 \\
\hline & TG5LE10 & .297 & .139 & .358 & 2.145 & .036 \\
\hline & GT10LE15 & .178 & .159 & .162 & 1.117 & .269 \\
\hline & LnAssets & -.050 & .038 & -.170 & -1.319 & .192 \\
\hline & Std Dev & .005 & .089 & .022 & .056 & .956 \\
\hline & Sharpe R & -.363 & .350 & -.176 & -1.037 & .304 \\
\hline & Beta & -.002 & .764 & -.001 & -.002 & .998 \\
\hline & Large & .042 & .345 & .050 & .122 & .904 \\
\hline & Medium & .029 & .264 & .032 & .109 & .913 \\
\hline & $\% \mathrm{R} 1 \mathrm{Yr}$ & .045 & .017 & .463 & 2.630 & .011 \\
\hline
\end{tabular}

a. Dependent Variable: Turnover 
Table 5. \%R3 Yr capitalization regression results

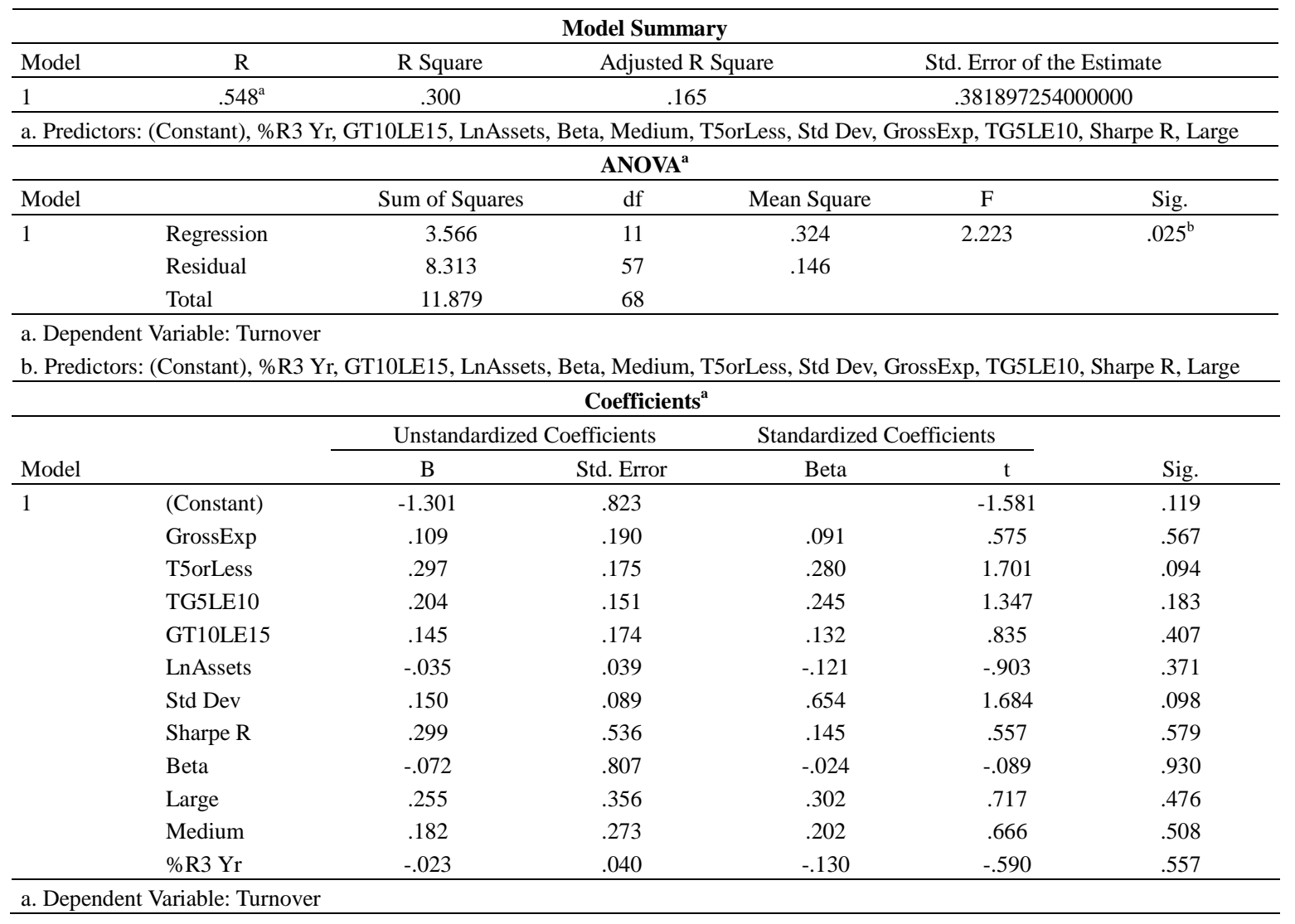

Table 6. \%R5Yr capitalization regression results

\begin{tabular}{|c|c|c|c|c|c|c|}
\hline \multicolumn{7}{|c|}{ Model Summary } \\
\hline Model & $\mathrm{R}$ & R Square & \multicolumn{2}{|c|}{ Adjusted R Square } & \multicolumn{2}{|c|}{ Std. Error of the Estimate } \\
\hline 1 & $.599^{\mathrm{a}}$ & .359 & \multicolumn{2}{|c|}{.236} & \multicolumn{2}{|c|}{.365418581000000} \\
\hline \multicolumn{7}{|c|}{ a. Predictors: (Constant), \%R5Yr, GrossExp, Medium, GT10LE15, Beta, Sharpe R, T5orLess, LnAssets, TG5LE10, Std Dev, Larg } \\
\hline \multicolumn{7}{|c|}{$\begin{array}{ll}\text { ANOVAa } \\
\end{array}$} \\
\hline Model & & Sum of Squares & df & Mean Square & $\mathrm{F}$ & Sig. \\
\hline \multirow[t]{3}{*}{1} & Regression & 4.268 & 11 & .388 & 2.906 & $.004^{\mathrm{b}}$ \\
\hline & Residual & 7.611 & 57 & .134 & & \\
\hline & Total & 11.879 & 68 & & & \\
\hline
\end{tabular}

a. Dependent Variable: Turnover

b. Predictors: (Constant), \%R5Yr, GrossExp, Medium, GT10LE15, Beta, Sharpe R, T5orLess, LnAssets, TG5LE10, Std Dev, Large

\begin{tabular}{|c|c|c|c|c|c|c|}
\hline \multicolumn{7}{|c|}{ Coefficients $^{\mathrm{a}}$} \\
\hline \multicolumn{2}{|c|}{ Model } & \multicolumn{2}{|c|}{ Unstandardized Coefficients } & \multicolumn{2}{|c|}{ Standardized Coefficients } & \multirow[b]{2}{*}{ Sig. } \\
\hline & & $\mathrm{B}$ & Std. Error & Beta & $\mathrm{t}$ & \\
\hline \multirow[t]{12}{*}{1} & (Constant) & -1.064 & .714 & & -1.491 & .141 \\
\hline & GrossExp & .071 & .182 & .059 & .392 & .696 \\
\hline & T5orLess & .424 & .167 & .400 & 2.537 & .014 \\
\hline & TG5LE10 & .218 & .138 & .263 & 1.583 & .119 \\
\hline & GT10LE15 & .158 & .161 & .144 & .981 & .331 \\
\hline & LnAssets & -.047 & .038 & -.162 & -1.249 & .217 \\
\hline & Std Dev & .067 & .081 & .292 & .825 & .413 \\
\hline & Sharpe R & -.009 & .317 & -.004 & -.029 & .977 \\
\hline & Beta & .476 & .803 & .156 & .593 & .556 \\
\hline & Large & -.060 & .363 & -.071 & -.165 & .869 \\
\hline & Medium & -.030 & .275 & -.033 & -.110 & .913 \\
\hline & $\% \mathrm{R} 5 \mathrm{Yr}$ & .038 & .016 & .310 & 2.374 & .021 \\
\hline
\end{tabular}

a. Dependent Variable: Turnover 
Table 7. \% R10Yr capitalization regression results

\begin{tabular}{|c|c|c|c|c|c|c|}
\hline \multicolumn{7}{|c|}{ Model Summary } \\
\hline Model & $\mathrm{R}$ & R Square & & Adjusted R Square & \multicolumn{2}{|c|}{ Std. Error of the Estimate } \\
\hline 1 & $.582^{\mathrm{a}}$ & .339 & & .211 & \multicolumn{2}{|c|}{.3712213650000} \\
\hline \multirow{2}{*}{\multicolumn{7}{|c|}{$\begin{array}{l}\text { a. Predictors: (Constant), \%R10Yr, Medium, GrossExp, T5orLess, Beta, GT10LE15, Sharpe R, LnAssets, TG5LE10, Std Dev, Large } \\
\text { ANOVAa }\end{array}$}} \\
\hline & & & & & & \\
\hline \multicolumn{2}{|c|}{ Model } & Sum of Squares & $\mathrm{df}$ & Mean Square & $\mathrm{F}$ & Sig. \\
\hline \multirow[t]{3}{*}{1} & Regression & 4.024 & 11 & .366 & \multirow[t]{3}{*}{2.655} & \multirow[t]{3}{*}{$.008^{\mathrm{b}}$} \\
\hline & Residual & 7.855 & 57 & .138 & & \\
\hline & Total & 11.879 & 68 & & & \\
\hline \multicolumn{7}{|c|}{$\begin{array}{l}\text { a. Dependent Variable: Turnover } \\
\text { b. Predictors: (Constant), \%R10Y }\end{array}$} \\
\hline \multicolumn{7}{|c|}{ Coefficients $^{\mathrm{a}}$} \\
\hline & & \multicolumn{2}{|c|}{ Unstandardized Coefficients } & \multicolumn{2}{|c|}{ Standardized Coefficients } & \multirow[b]{2}{*}{ Sig. } \\
\hline Model & & $\mathrm{B}$ & Std. Error & Beta & $\mathrm{t}$ & \\
\hline \multirow{12}{*}{1} & (Constant) & -.877 & .734 & & -1.196 & 237 \\
\hline & GrossExp & .076 & .185 & .063 & .411 & .683 \\
\hline & T5orLess & .407 & .170 & .384 & 2.397 & .020 \\
\hline & TG5LE10 & .309 & .146 & .372 & 2.122 & .038 \\
\hline & GT10LE15 & .134 & .164 & .123 & .818 & .416 \\
\hline & LnAssets & -.049 & .039 & -.169 & -1.269 & .210 \\
\hline & Std Dev & .083 & .081 & .362 & 1.019 & .312 \\
\hline & Sharpe R & -.124 & .334 & -.060 & -.372 & .711 \\
\hline & Beta & .387 & .817 & .127 & .474 & .637 \\
\hline & Large & .028 & .363 & .033 & .076 & .939 \\
\hline & Medium & .007 & .279 & .008 & .025 & .980 \\
\hline & $\% \mathrm{R} 10 \mathrm{Yr}$ & .044 & .023 & .286 & 1.922 & .060 \\
\hline
\end{tabular}

Similar regression was run with the style dimension; the results are presented in Tables 8 through 12 . The adjusted $\mathrm{R}^{2}$ ranged from $16.5(\mathrm{p}$-value $=0.01)$ for the three-year return to $25.1(\mathrm{p}$-value $=0.003)$ for the one-year return. In all the regressions, only the T5orless and the TG5LE10 variables were significant. The coefficients for the 5-years or less manager's tenure ranged from 0.28 (p-value of 0.094 ) for the three-year return to 0.4 (p-value of 0.014 ) for the five-year return. The average coefficient was 0.3428 . For the five to 10 -year manager's tenure, the coefficients ranged from 0.245 (p-value of 0.183 ) for the 3-year return to 0.372 (p-value of 0.038 ) for the 10 -year return. The average coefficient was 0.3046 . Of the five return variables, only the 3 -year return was not significant in explaining the variation in the portfolio turnover. The one-year return had the highest coefficient at 0.463 and a p-value of 0.011 .

Table 8. \%YTD style objective regression results

\begin{tabular}{|c|c|c|c|c|c|c|}
\hline \multicolumn{7}{|c|}{ Model Summary } \\
\hline Model & $\mathrm{R}$ & R Square & \multicolumn{2}{|c|}{ Adjusted R Square } & \multicolumn{2}{|c|}{ Std. Error of the Estimate } \\
\hline 1 & $.575^{\mathrm{a}}$ & .331 & \multicolumn{2}{|c|}{.202} & \multicolumn{2}{|c|}{.373483557000000} \\
\hline \multicolumn{7}{|c|}{ a. Predictors: (Constant), \%YTD, GrossExp, T5orLess, Blend, GT10LE15, Std Dev, LnAssets, Beta, TG5LE10, Value, Sharpe R } \\
\hline \multicolumn{7}{|c|}{ ANOVA $^{\mathrm{a}}$} \\
\hline Model & & Sum of Squares & $\mathrm{df}$ & Mean Square & $\mathrm{F}$ & Sig. \\
\hline \multirow[t]{3}{*}{1} & Regression & 3.928 & 11 & .357 & 2.560 & $.010^{\mathrm{b}}$ \\
\hline & Residual & 7.951 & 57 & .139 & & \\
\hline & Total & 11.879 & 68 & & & \\
\hline \multicolumn{7}{|c|}{$\begin{array}{l}\text { a. Dependent Variable: Turnover } \\
\text { b. Predictors: (Constant), \%YTD, GrossExp, T5orLess, Blend, GT10LE15, Std Dev, LnAssets, Beta, TG5LE10, Value, Sharpe R }\end{array}$} \\
\hline \multicolumn{7}{|c|}{ Coefficients $^{\mathrm{a}}$} \\
\hline \multirow[b]{2}{*}{ Model } & & \multicolumn{2}{|c|}{ Unstandardized Coefficients } & \multicolumn{2}{|c|}{ Standardized Coefficients } & \multirow[b]{2}{*}{ Sig. } \\
\hline & & B & Std. Error & Beta & $\mathrm{t}$ & \\
\hline \multirow[t]{12}{*}{1} & (Constant) & -.382 & .764 & & -.501 & .618 \\
\hline & GrossExp & .090 & .193 & .075 & .469 & .641 \\
\hline & T5orLess & .328 & .166 & .309 & 1.978 & .053 \\
\hline & TG5LE10 & .246 & .137 & 297 & 1.802 & .077 \\
\hline & GT10LE15 & .185 & 161 & .169 & 1.146 & 257 \\
\hline & LnAssets & -.045 & .040 & -.155 & -1.124 & .266 \\
\hline & Std Dev & .070 & .043 & .304 & 1.621 & .110 \\
\hline & Sharpe R & -.244 & .378 & -.118 & -.646 & .521 \\
\hline & Beta & .138 & .458 & .045 & .301 & .765 \\
\hline & Value & .027 & .157 & .031 & .173 & .863 \\
\hline & Blend & .055 & 135 & .062 & .404 & .688 \\
\hline & $\%$ YTD & .030 & .017 & .292 & 1.717 & .091 \\
\hline
\end{tabular}


Table 9. \%R1Yr style objective regression results

\begin{tabular}{|c|c|c|c|c|c|c|}
\hline \multicolumn{7}{|c|}{ Model Summary } \\
\hline Model & $\mathrm{R}$ & R Square & \multicolumn{2}{|c|}{ Adjusted R Square } & \multicolumn{2}{|c|}{ Std. Error of the Estimate } \\
\hline 1 & $.617^{\mathrm{a}}$ & .381 & \multicolumn{2}{|c|}{.261} & \multicolumn{2}{|c|}{.3592385460000} \\
\hline \multicolumn{7}{|c|}{ a. Predictors: (Constant), \%Re1 Yr, T5orLess, Sharpe R, GT10LE15, LnAssets, Blend, Beta, Value, GrossExp, TG5LE10, Std Dev } \\
\hline \multicolumn{7}{|c|}{ ANOVA $^{\text {a }}$} \\
\hline Model & & Sum of Squares & df & Mean Square & $\mathrm{F}$ & Sig. \\
\hline \multirow[t]{3}{*}{1} & Regression & 4.523 & 11 & .411 & 3.186 & $.002^{\mathrm{b}}$ \\
\hline & Residual & 7.356 & 57 & .129 & & \\
\hline & Total & 11.879 & 68 & & & \\
\hline \multicolumn{7}{|c|}{$\begin{array}{l}\text { a. Dependent Variable: Turnover } \\
\text { b. Predictors: (Constant), \%R1 Yr, T5orLess, Sharp }\end{array}$} \\
\hline b. Predi & rs: (Constant) & r, T5orLess, Sharp & , GT10LE15 & ssets, Blend, B & e, GrossEx & 0, Std Dev \\
\hline \multicolumn{7}{|c|}{ Coefficients $^{\mathrm{a}}$} \\
\hline & & \multicolumn{2}{|c|}{ Unstandardized Coefficients } & \multicolumn{2}{|c|}{ Standardized Coefficients } & \\
\hline Model & & $\mathrm{B}$ & Std. Error & Beta & $\mathrm{t}$ & Sig. \\
\hline \multirow[t]{12}{*}{1} & (Constant) & .438 & .820 & & .535 & .595 \\
\hline & GrossExp & .082 & .185 & .068 & .445 & .658 \\
\hline & T5orLess & .388 & .161 & .366 & 2.414 & .019 \\
\hline & TG5LE10 & .303 & .133 & .365 & 2.283 & .026 \\
\hline & GT10LE15 & .181 & .155 & .165 & 1.165 & .249 \\
\hline & LnAssets & -.044 & .038 & -.151 & -1.167 & .248 \\
\hline & Std Dev & -.023 & .052 & -.099 & -.438 & .663 \\
\hline & Sharpe R & -.547 & .390 & -.266 & -1.405 & .165 \\
\hline & Beta & .101 & .424 & .033 & .238 & .813 \\
\hline & Value & -.121 & .134 & -.136 & -.901 & .371 \\
\hline & Blend & -.050 & .117 & -.057 & -.427 & .671 \\
\hline & $\% \mathrm{R} 1 \mathrm{Yr}$ & .047 & .017 & .476 & 2.792 & .007 \\
\hline
\end{tabular}

Table 10. \%R3Yr style objective regression results

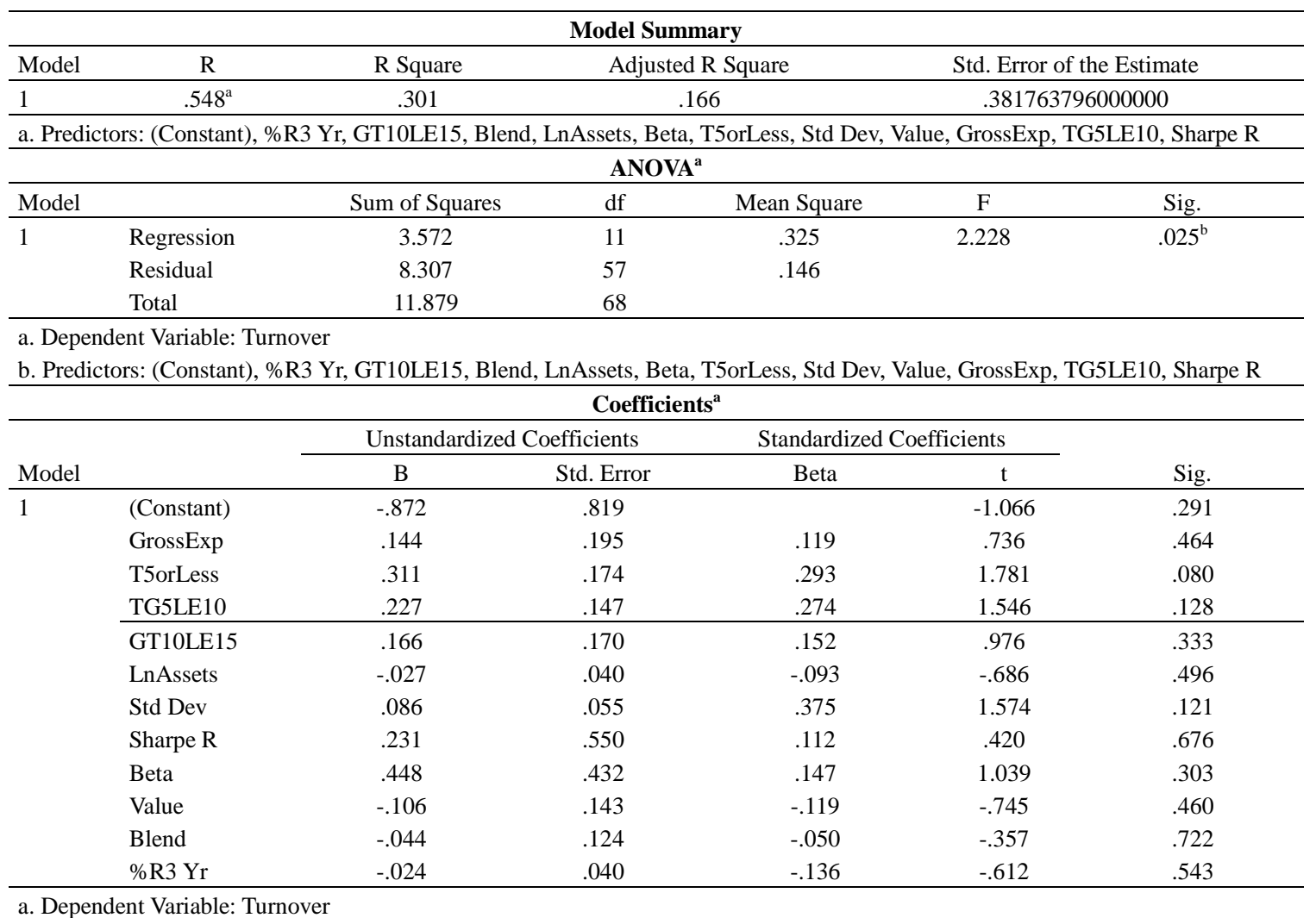


Table 11. \%R5Yr style objective regression results

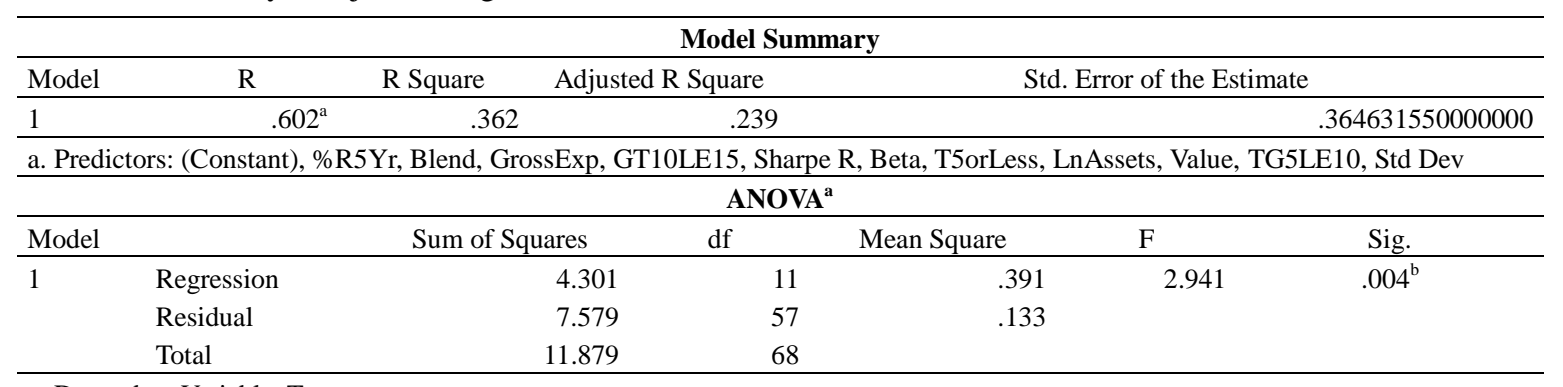

a. Dependent Variable: Turnover

b. Predictors: (Constant), \%R5Yr, Blend, GrossExp, GT10LE15, Sharpe R, Beta, T5orLess, LnAssets, Value, TG5LE10, Std Dev

\begin{tabular}{|c|c|c|c|c|c|c|c|}
\hline \multicolumn{8}{|c|}{ Coefficients $^{\mathrm{a}}$} \\
\hline & & \multicolumn{2}{|c|}{ Unstandardized Coefficients } & \multicolumn{2}{|c|}{ Standardized Coefficients } & \multirow[b]{2}{*}{ Sig. } & \\
\hline \multicolumn{2}{|c|}{ Model } & B & Std. Error & Beta & $\mathrm{t}$ & & \\
\hline \multirow[t]{12}{*}{1} & (Constant) & -.905 & .731 & & -1.239 & .221 & \\
\hline & GrossExp & .107 & .187 & .089 & .574 & .568 & \\
\hline & T5orLess & .418 & .166 & .394 & 2.525 & .014 & \\
\hline & TG5LE10 & .214 & .135 & .257 & 1.587 & .118 & \\
\hline & GT10LE15 & .154 & .158 & .140 & .970 & .336 & \\
\hline & LnAssets & -.044 & .039 & -.151 & -1.140 & .259 & \\
\hline & Std Dev & .066 & .042 & .290 & 1.586 & .118 & \\
\hline & Sharpe R & -.144 & .350 & -.070 & -.412 & .682 & \\
\hline & Beta & .388 & .413 & .127 & .940 & .351 & \\
\hline & Value & -.072 & .136 & -.081 & -.530 & .598 & \\
\hline & Blend & -.024 & .119 & -.028 & -.205 & .838 & \\
\hline & $\% \mathrm{R} 5 \mathrm{Yr}$ & .036 & .015 & & 2.427 & & .018 \\
\hline
\end{tabular}

a. Dependent Variable: Turnover

Table 12. \%R10Yr style objective regression results

\begin{tabular}{|c|c|c|c|c|c|c|}
\hline \multicolumn{7}{|c|}{ Model Summary } \\
\hline Model & $\mathrm{R}$ & R Square & \multicolumn{2}{|c|}{ Adjusted R Square } & \multicolumn{2}{|c|}{ Std. Error of the Estimate } \\
\hline 1 & $.583^{\mathrm{a}}$ & .340 & \multicolumn{2}{|c|}{.213} & \multicolumn{2}{|c|}{.370879407000000} \\
\hline \multicolumn{7}{|c|}{ a. Predictors: (Constant), \%R10Yr, GrossExp, Value, T5orLess, Beta, GT10LE15, Sharpe R, LnAssets, Blend, TG5LE10, Std De } \\
\hline \multicolumn{7}{|c|}{ ANOVA $^{\mathrm{a}}$} \\
\hline Model & & Sum of Squares & df & Mean Square & $\mathrm{F}$ & Sig. \\
\hline \multirow[t]{3}{*}{1} & Regression & 4.039 & 11 & .367 & 2.669 & $.008^{\mathrm{b}}$ \\
\hline & Residual & 7.840 & 57 & .138 & & \\
\hline & Total & 11.879 & 68 & & & \\
\hline
\end{tabular}

a. Dependent Variable: Turnover

b. Predictors: (Constant), \%R10Yr, GrossExp, Value, T5orLess, Beta, GT10LE15, Sharpe R, LnAssets, Blend, TG5LE10, Std Dev

\begin{tabular}{|c|c|c|c|c|c|c|}
\hline \multicolumn{7}{|c|}{ Coefficients $^{\mathrm{a}}$} \\
\hline & & \multicolumn{2}{|c|}{ Unstandardized Coefficients } & \multicolumn{2}{|c|}{ Standardized Coefficients } & \multirow[b]{2}{*}{ Sig. } \\
\hline \multicolumn{2}{|c|}{ Model } & $\mathrm{B}$ & Std. Error & Beta & $\mathrm{t}$ & \\
\hline \multirow[t]{12}{*}{1} & (Constant) & -.771 & .739 & & -1.043 & .301 \\
\hline & GrossExp & .092 & .191 & .076 & .480 & .633 \\
\hline & T5orLess & .414 & .170 & .390 & 2.441 & .018 \\
\hline & TG5LE10 & .310 & .139 & .374 & 2.237 & .029 \\
\hline & GT10LE15 & .137 & .163 & .125 & .845 & .402 \\
\hline & LnAssets & -.046 & .040 & -.157 & -1.153 & .254 \\
\hline & Std Dev & .072 & .043 & .316 & 1.695 & .096 \\
\hline & Sharpe R & -.167 & .360 & -.081 & -.464 & .645 \\
\hline & Beta & .431 & .419 & .141 & 1.027 & .309 \\
\hline & Value & -.044 & .141 & -.049 & -.311 & .757 \\
\hline & Blend & -.002 & .123 & -.003 & -.019 & .985 \\
\hline & $\% \mathrm{R} 10 \mathrm{Yr}$ & .043 & .022 & .282 & 1.947 & .056 \\
\hline
\end{tabular}


The results of the style dimension regression are similar to those of the capitalization regression. The two major significant predictors of the portfolio turnover continue to be the manager's variables. The coefficient of T5orLess ranges from 0.293 with a p-value of 0.08 for $\% \mathrm{R} 3 \mathrm{Yr}$ to 0.394 with a p-value of 0.014 for \% R5Yr return variable. The average coefficient was 0.3504 . Similarly, for TG5LE10 variable, the coefficients ranged from 0.257 with a p-value of 0.118 for $\% \mathrm{R} 5 \mathrm{Yr}$ to 0.374 with a p-value of 0.029 for $\% \mathrm{R} 10 \mathrm{Yr}$. The average coefficient was 0.3134 . Of the five return variables, only the 3 -year return was not significant in explaining the variation in the portfolio turnover. The one-year return had the highest coefficient at 0.476 and a p-value of 0.007 . The average adjusted $\mathrm{R}^{2}$ was $21.64 \%$. Unlike the capitalization regression, the style regression showed that Std Dev was marginally significant in explaining the variation in turnover. The most significant was in the \% R $10 \mathrm{Yr}$ regression with a coefficient of 0.316 and a p-value of 0.096 .

To further understand the regression results, a Pearson's correlation analysis was performed. The correlation matrix for all the variables is presented in Table 13. The results indicate a strong a positive correlation between turnover and the following: \%R1Yr, Std Dev, and Beta, and a negative correlation with LnAssets. In addition, there is a highly significant correlation between the returns except the \% R5Yr return.

Table 13. Pearson's correlation matrix

\begin{tabular}{|c|c|c|c|c|c|c|c|c|c|c|c|}
\hline \multicolumn{12}{|c|}{ Correlations } \\
\hline & $\%$ YTD & $\%$ r1Yr & $\% \mathrm{r} 3 \mathrm{Yr}$ & $\% \mathrm{R} 5 \mathrm{Yr}$ & $\% \mathrm{R} 10 \mathrm{Yr}$ & GroseExp & LnAssets & Turnover & Std Dev & Sharpe R & Beta \\
\hline \multirow[t]{2}{*}{$\%$ YTD } & 1 & $.503^{* *}$ & $.475^{* *}$ & .183 & $.382^{* *}$ & -.027 & $.247^{*}$ & .141 & -.141 & $.578^{* *}$ & .187 \\
\hline & & .000 & .000 & .126 & .001 & .824 & .038 & .242 & .241 & .000 & .123 \\
\hline \multirow[t]{2}{*}{$\% \mathrm{R} 1 \mathrm{Yr}$} & & 1 & $.542^{* *}$ & .026 & .092 & $.285^{*}$ & -.037 & $.435^{* *}$ & $.561^{* *}$ & .158 & $.356^{* * *}$ \\
\hline & & & .000 & .829 & .446 & .016 & .543 & .000 & .000 & .187 & .003 \\
\hline \multirow[t]{2}{*}{$\% \mathrm{R} 3 \mathrm{Yr}$} & & & 1 & .068 & $.289^{*}$ & $.309^{* *}$ & -.048 & .068 & .186 & $.627^{* *}$ & .033 \\
\hline & & & & .571 & .014 & .009 & .689 & .574 & .120 & .000 & .785 \\
\hline \multirow[t]{2}{*}{$\% \mathrm{R} 5 \mathrm{Yr}$} & & & & 1 & $.585^{* *}$ & .042 & .169 & .106 & -.105 & .103 & -.069 \\
\hline & & & & & .000 & .727 & .158 & .378 & .384 & .392 & .573 \\
\hline \multirow[t]{2}{*}{$\% \mathrm{R} 10 \mathrm{Yr}$} & & & & & 1 & .117 & .208 & -.027 & $-.257^{*}$ & $.365^{* *}$ & -.217 \\
\hline & & & & & & .331 & .081 & .824 & .031 & .002 & .074 \\
\hline \multirow[t]{2}{*}{ GroseExp } & & & & & & 1 & $-.465^{* *}$ & .182 & $.327^{* *}$ & .070 & $-.283^{*}$ \\
\hline & & & & & & & .000 & .129 & .005 & .559 & .019 \\
\hline \multirow[t]{2}{*}{ LnAssets } & & & & & & & 1 & $-.270^{*}$ & $-359^{* *}$ & .208 & .022 \\
\hline & & & & & & & & .023 & .002 & .081 & .858 \\
\hline \multirow[t]{2}{*}{ Turnover } & & & & & & & & 1 & $.432^{* *}$ & -.170 & $.275^{*}$ \\
\hline & & & & & & & & & .000 & .157 & .022 \\
\hline \multirow[t]{2}{*}{ Std Dev } & & & & & & & & & 1 & $-.510^{* *}$ & $.372^{* *}$ \\
\hline & & & & & & & & & & .000 & .002 \\
\hline \multirow[t]{2}{*}{ Sharpe R } & & & & & & & & & & 1 & -.225 \\
\hline & & & & & & & & & & & .065 \\
\hline Beta & & & & & & & & & & & 1 \\
\hline
\end{tabular}

\section{Conclusion}

The objective of this study was to investigate the factors that correlated with mutual fund portfolio turnover using the variables that are associated with studies on portfolio turnover. Most studies on portfolio turnover considered it as an independent variable in explaining the performance of mutual funds. We take a different approach and treat turnover as the dependent variable. Our regression analysis show that the portfolio manager's tenure explains the variability in portfolio turnover. We find that when the manager's tenure is equal to or less than ten years explains there is a strong tendency for the manager to actively trade and hence have a high portfolio turnover, to enhance the performance of the portfolio. A plausible explanation might be that young managers especially under five years want to take ownership of the portfolio and implement their own investment strategy. We also find that the one-, five-, and ten-year returns are statistically significant in explaining the variation in portfolio turnover. In addition, we find that when the analysis was performed using style objectives, that standard deviation was marginally significant in explaining portfolio turnover given the returns. We also find that total asset under management has a negative impact on portfolio turnover; the larger the portfolio assets, the less the portfolio turnover. This finding supports the notion of the inertia of large portfolio and the difficulty involved in trading the large holdings quickly. 
This study contributes to the literature by providing evidence on why portfolio managers continue to trade actively despite the evidence that portfolio turnover does not on average enhance returns after costs.

\section{References}

Baunan, W. S., Miller, R. E., \& Veit, E. T. (2005). Managing Portfolio Turnover: An Empirical Study. Quarterly Journal of Business and Economics, 44(3/4), 15-31.

Bello, Z., \& DeRidder, J. J. (2011). The effects of portfolio concentration on investment performance of actively managed domestic equity mutual funds, 1990 to 2010. Global Journal of International Business Research 4(4), 34-47.

Bliss, R. T., Potter, M. E., \& Schwarz, C. (2008). Performance Characteristics of Individually-Managed versus Team-Managed Mutual Funds. Journal of Portfolio Management, 34(3), 110-132. https://doi.org/10.3905/jpm.2008.706248

Cakici, N., Tessitore, A., \&Usmen, N. (2002). Closed-end funds and turnover restrictions. Financial Analysts Journal, 58(3), 74-81. https://doi.org/10.2469/faj.v58.n3.2539

Chang, C. E., Nelson, W. A., \& Witte, H. D. (2012). Do green mutual funds perform well? Management Research Review, 35(8), 693-708. http://dx.doi.org/10.1108/01409171211217695

Chou, W. H., \& Hardin III, W. G. (2014). Performance Chasing, Fund Flows and Fund Size in Real Estate Mutual Funds. J. Real Estate Finan Econ., 49, 379-412. hppt://dx.doi.org/10.1007/s11146-013-9444-x

Evans, A. L. (2008). Portfolio Manager Ownership and Mutual Fund Performance. Financial Management, 37(3), 513-534. https://doi.org/10.1111/j.1755-053X.2008.00023.x

Fan, Y., \& Addams, H. L. (2012). United States-based international mutual funds; Performance and persistence. Financial Services Review, 21(1), 51-61.

Haslem, J. A., Baker, H. K., \& Smith, D. M. (2008). Performance and characteristics of actively managed retail equity mutual funds with diverse expense rations. Financial Services Review, 17(1), 49-68.

Ippolito, R. A., \& Turner, J. A. (1987). Turnover, Fees and Pension Plan Performance. Financial Analysts Journal, 43(6), 16-26. https://doi.org/10.2469/faj.v43.n6.16

Kaushik, A., \& Barnhart, S. W. (2009). Do mutual funds with few holdings outperform the market? Journal of Asset Management, 9(6), 398-408. http://dx.doi.org/10.1057/jam.2008.39

Low, S. W. (2008). A cross-sectional analysis of Malaysian unit trust fund expense ratios. Journal of Asset Management, 9(4), 270-277. hppt://dx.doi.org/10.1057/jam.2008.25

Peterson, J. D., \& Riepe, M. W. (2007). Does the Turnover of an Equity Mutual Matter? Journal of Financial Planning, 20(8), 32-33

Redman, A. L., \& Gullett, N. S. (2007). Impact of fund, management and market characteristics on bond mutual fund performance. Journal of Asset Management; 7(6), 429-442. hppt://dx.doi.org/10.1057/palgrave.jam.2250053

Taylor, W. R. L., \& Yoder, J. A. (1994). Mutual fund trading activity and investor utility. Financial Analysts Journal, 50(3), 66-69. https://doi.org/10.2469/faj.v50.n3.66

Tower, E., \& Zheng, W. (2008). Ranking mutual fund families: minimum expenses and maximum loads as markers for moral turpitude. International Review of Economics, 55, 315-350. http://dx.doi.org/10.1007/s12232-008-0052-7

\section{Copyrights}

Copyright for this article is retained by the author(s), with first publication rights granted to the journal.

This is an open-access article distributed under the terms and conditions of the Creative Commons Attribution license (http://creativecommons.org/licenses/by/4.0/). 